\title{
Effect of Transcutaneous Electrical Nerve Stimulation on Pruritus in Lichen Planus Patient \\ Nessrien Afifi ${ }^{1}$, Mohammed Lotfy Elsaie ${ }^{2}$, Marwa Mahdy Abd EL-Hameed, Ghada Magdy Abd Elrhim ${ }^{1}$ \\ ${ }^{1}$ Department of Physical Therapy for Surgery, ${ }^{2}$ National Research Center, Faculty of Physical Therapy, Cairo University, Giza, Egypt
}

*Corresponding author: Ghada Magdy Abd Elrhim, Mobile: (+20)1154968268, E-Mail: ghadamagdy1982@gmail.com

\begin{abstract}
Background: Lichen planus is a chronic inflammatory and immune mediated disease that is usually intensely pruritic, and this symptom does not subside after common antipruritic treatment.

Objective: The purpose of the study was to evaluate the therapeutic effect of transcutaneous electrical nerve stimulation on lichen planus patient.

Patients and methods: Thirty patients who had lichen planus with age ranged from 20-40 years were selected randomly from El-Saff Hospital, only who agreed to be volunteers participated in the study and were randomized into two groups of equal number, 15 patient for each group. Group (A) received medical medication and transcutaneous electrical nerve stimulation (TENS): frequency $100 \mathrm{~Hz}$, with the duration of each session being $1 \mathrm{~h}$, administered on 3 days/week for 4 weeks and intensity of TENS was according to patient tolerance and Group (B) who only received the same medical medication only.
\end{abstract}

Results: Compared to result before and after TENS treatment, our study showed that there was significant decrease in the results of visual analogue scale (VAS) and Dermatology Life Quality Index (DLQI); but the result of group (A) were superior to that of group (B) when comparing the groups' results together.

Conclusion: TENS was beneficial and had a good effect on pruritus in lichen planus patients.

Keywords: Lichen Planus, Pruritus, Transcutaneous electrical nerve stimulation, Visual Analogue Scale.

\section{INTRODUCTION}

Lichen planus (LP) is a chronic inflammatory papulosquamous skin, nail, hair, and mucous membrane disorder with a wide range of severity and progression. The LP rash is defined by the ' 5 Ps': pruritic, planar, purple, polygonal papules with well-defined borders ${ }^{(\mathbf{1})}$. Many variants of LP exist, differentiated on the basis of the morphology of lesions and body site (s) involved. The disease can negatively affect the quality of life of patients, particularly forms such as hypertrophic LP and erosive oral LP ${ }^{(2)}$. The cause is unknown, although it's assumed to be the outcome of an autoimmune reaction that started with an unknown trigger. Although there is no cure, several drugs and surgeries have been tried to control the symptoms ${ }^{(3)}$.

Pruritus is the most prevalent symptom of skin disorders, sometimes trifling or light, and sometimes intolerable. It includes a variety of clinic complaints encompassing dermatologic, neurologic, systemic, and mental problems ${ }^{(4)}$. Itching, or pruritus, is a frequent and occasionally irritating symptom of a variety of dermatological conditions. Cutaneous LP is notoriously pruritic, and current antipruritic treatments rarely alleviate this condition. Pruritus is a common symptom of LP skin lesions, which can include things like decreased psychophysical activity, sadness, dread, and tension $^{(5)}$.

Itch, sometimes called pruritus, is a cutaneous feeling that is not the same as pain. Different subgroups of specialised primary afferent C-fibers, including both histamine-sensitive and histamine-insensitive non nociceptive polymodal nerve fibres, are activated by pruritogenic stimuli, while nociceptive polymodal fibres are also implicated to some extent ${ }^{(\boldsymbol{6})}$.

TENS treatment has recently been shown to have an antipruritic effect on lichen planus. TENS is a noninvasive and safe therapy for itching caused by LP ${ }^{(7)}$. TENS is a non-invasive, non-pharmacological therapy that has recently been presented as a possible treatment for pruritic dermatoses ${ }^{(\boldsymbol{8})}$. In dermatology, the most prevalent use of TENS therapy is to relieve itching. TENS may have an antipruritic impact in itchy skin diseases since pain and pruritus are two sensations that are comparable at the peripheral and central levels ${ }^{(9)}$.

The aim of this study was to evaluate the therapeutic effect of transcutaneous electrical nerve stimulation (TENS) on lichen planus patient.

\section{PATIENTS AND METHODS}

Thirty patient ( 8 male and 22 female) were enrolled in the study. They were selected from the Outpatient Dermatology of El-Saff Hospital with mean age of 40 years. Random allocations were determined by a computer-generated random number program.

Group (A) included 15 patients who received medical treatments and TENS and Group (B) who received medical treatments. All of the patients had a history of itching attacks that were limited to one place and caused them to scratch or massage that area a lot. Patients received a physical examination and provided a 
complete medical history, including demographic information (e.g. name, sex, age, address, occupation) and clinical itch aspects (e.g. frequency and duration of itch, existence of sleep disturbance and the most common itch provoking conditions). The disease's duration and location, as well as past therapies, were all documented.

\section{Ethical approval:}

Research Ethics Committee and Quality Control (Cairo University) approvals were obtained. The study purpose and procedures were explained in details and in plain terms to each of the subjects before being asked to give an informed written consent to participate in the study. Quality control of screening, handling of data and verification of adherence to protocols were done on a regular basis by the trial coordinator.

Inclusion Criteria: The patients' ages ranged from 25 to 40, duration of LP less than 1 year, disease affecting the back, arms, and/or legs (patient may have more than one affected area), and they experienced chronic, recurrent pruritus for which they had been treated with corticosteroids and systemic antihistamines but had not seen a significant improvement.

Exclusion criteria: The study excluded patients with any of the following: Pregnancy or breast-feeding, any other inflammatory skin disorders or systemic conditions that cause pruritus, such as metabolic or chronic kidney disease, or an implanted cardiac pacemaker, reduction of sensation in the treatment, and the presence of erosive oral LP, significant nail involvement, or planopilar lichen.

\section{Procedures of the study:}

The procedures of the study was divided into two main procedures.

\section{A) Measurement procedures:}

For both groups, VAS and DLQI assessment were performed at baseline and after 4 weeks and after one month after end of treatment. The Visual Analogue Scale (VAS) appears to be one of the most often utilised measures for determining the degree of pruritus since it allows for a simple and quick assessment of itch ${ }^{(\mathbf{1 0})}$.

The DLQI was created to identify limits linked to the impact of skin disease and its treatment. It consists of ten items and covers six domains that includes symptoms and feelings, daily activities, relaxation, job and education, personal relationships, and treatment. Response categories include "'not at all,' " a little,' "'a lot," and "very much," with corresponding scores of 0 , 1,2 , and 3. The responses "not relevant" and unanswered items are rated as ' 0 " respectively. A total score is derived by adding the scores of all phrases, obtaining a maximum score of 30 and a minimum score of 0 . High scores suggest greater impairment ${ }^{(11)}$.

\section{Measurements have been taken as following:}

At baseline and after 4 weeks and one month after end of treatment.

\section{B) Therapeutic procedures:}

For group A, patients were not allowed to take systemic therapy, such as topical cortisol derivatives, for 2 weeks before to TENS administration or during the test period. During the treatment, they were allowed to use creams. Following that, participants received medical treatment (topical corticosteroid and histamine inhibitors) as well as TENS application during the study. Throughout each patient's treatment sessions, TENS electrodes were put to the itchiest skin lesion and to the same itchy lesion. For electrical impulse conduction, a gel-based coupling agent was used. To establish proper contact, elastic bandages were applied around the sites to press the electrodes into the skin.

\section{TENS parameter:}

The frequency was set to $100 \mathrm{~Hz}$, the duration of each session was one hour, and the intensity of the TENS was adjusted to the patient's tolerance to avoid uncomfortable, jerking, involuntary muscle movements. Any AEs, such as erythema, edema, irritation, or numbness, were to be reported by the patients. Session frequency: 3 days per week for 4 weeks.

For group B, participants received topical corticosteroid and histamine inhibitors.

\section{Statistical analysis}

Data were fed to the computer and analyzed using IBM SPSS software package version 20.0. (Armonk, NY: IBM Corp). Qualitative data were described using number and percent.

The Kolmogorov-Smirnov test was used to verify the normality of distribution. Chi square test $(\chi 2)$ to calculate difference between two or more groups of qualitative variables. Quantitative data were described using range (minimum and maximum), mean, standard deviation, median and interquartile range (IQR). Significance of the obtained results was judged at the $5 \%$ level. $\mathrm{P}$ value $<0.05$ was considered significant.

\section{RESULTS \\ Subject characteristics:}

The participant demographic data are presented in table 1 . There was no statistical significant difference between groups as regard sex, age and site.

Table (1): Comparison between the two studied groups according to demographic data 


\begin{tabular}{|c|c|c|c|c|c|c|}
\hline \multirow[t]{2}{*}{ Demographic data } & \multicolumn{2}{|c|}{$\begin{array}{c}\text { Study group } \\
(\mathbf{n}=15)\end{array}$} & \multicolumn{2}{|c|}{$\begin{array}{c}\text { Control group } \\
(\mathbf{n}=15)\end{array}$} & \multirow[t]{2}{*}{$\chi^{2}$} & \multirow[t]{2}{*}{$\mathbf{P}$} \\
\hline & No. & $\%$ & No. & $\%$ & & \\
\hline \multicolumn{7}{|l|}{ Sex } \\
\hline Female & 11 & 73.3 & 11 & 73.3 & \multirow{2}{*}{$\begin{array}{c}\chi 2= \\
0.000\end{array}$} & \multirow{2}{*}{$\begin{array}{l}\text { FEp }= \\
1.000\end{array}$} \\
\hline Male & 4 & 26.7 & 4 & 26.7 & & \\
\hline \multicolumn{7}{|l|}{ Age } \\
\hline$<30$ & 5 & 33.3 & 5 & 33.3 & \multirow{5}{*}{$\begin{array}{c}\chi 2= \\
0.530\end{array}$} & \multirow{5}{*}{$\begin{array}{c}\mathrm{MCp}= \\
1.000\end{array}$} \\
\hline $30-<40$ & 9 & 60.0 & 8 & 53.3 & & \\
\hline$\geq 40$ & 1 & 6.7 & 2 & 13.3 & & \\
\hline Mean \pm SD & \multicolumn{2}{|c|}{$32.20 \pm 4.77$} & \multicolumn{2}{|c|}{$33.60 \pm 6.19$} & & \\
\hline Median (IQR) & \multicolumn{2}{|c|}{$\begin{array}{c}32.0 \\
(28.50-35.50)\end{array}$} & \multicolumn{2}{|c|}{$\begin{array}{c}33.0 \\
(28.50-37.50)\end{array}$} & & \\
\hline \multicolumn{7}{|l|}{ Site } \\
\hline Arm & 5 & 33.3 & 5 & 33.3 & \multirow{3}{*}{$\begin{array}{c}\chi 2= \\
0.394\end{array}$} & \multirow{3}{*}{$\begin{array}{c}\mathrm{MCp}= \\
1.000\end{array}$} \\
\hline Back & 2 & 13.3 & 3 & 20.0 & & \\
\hline Leg & 8 & 53.3 & 7 & 46.7 & & \\
\hline
\end{tabular}

\section{Effect of treatment on VAS and DLQI:}

For group A there was highly statistical significant difference between the three periods. Furthermore, there was highly statistical significant difference between baseline and each of after one month and one month after end of treatment, while there was non-significant difference between after month and at one month after end of treatment as regard VAS. On the other hand, for Group B, there was highly statistical significant difference between the studied periods according to visual analogue scale (Table 2).

Table (2): Comparison between the studied periods according to visual analogue scale

\begin{tabular}{|c|c|c|c|c|c|}
\hline Visual Analogue Scale & Baseline & $\begin{array}{l}\text { After one } \\
\text { month of } \\
\text { treatment }\end{array}$ & $\begin{array}{l}\text { One month after } \\
\text { end of treatment }\end{array}$ & $\mathbf{F}$ & $\mathbf{P}$ \\
\hline \multicolumn{6}{|l|}{ Study group A } \\
\hline Mean \pm SD. & $7.53 \pm 1.68$ & $2.47 \pm 1.06$ & $2.20 \pm 1.01$ & \multirow[t]{2}{*}{151.319} & \multirow[t]{2}{*}{$<0.001^{*}$} \\
\hline Median (IQR) & $\begin{array}{c}8.0 \\
(6.0-9.0)\end{array}$ & $\begin{array}{c}2.0 \\
(2.0-3.0)\end{array}$ & $\begin{array}{c}2.0 \\
(1.50-3.0)\end{array}$ & & \\
\hline $\mathrm{P}$ between periods & \multicolumn{3}{|c|}{$\mathrm{p} 1<0.001^{*}, \mathrm{p} 2<0.001^{*}, \mathrm{p} 3=1.000$} & & \\
\hline \multicolumn{6}{|l|}{ Control group B } \\
\hline Mean \pm SD & $7.87 \pm 1.46$ & $4.07 \pm 1.03$ & $3.27 \pm 1.10$ & \multirow[t]{2}{*}{130.315} & \multirow[t]{2}{*}{$<0.001^{*}$} \\
\hline Median (IQR) & $8.0(7.0-9.0)$ & $4.0(3.50-5.0)$ & $3.0(3.0-4.0)$ & & \\
\hline $\mathrm{P}$ between periods & \multicolumn{3}{|c|}{$\mathrm{p} 1<0.001^{*}, \mathrm{p} 2<0.001^{*}, \mathrm{p} 3=0.026^{*}$} & & \\
\hline
\end{tabular}

\section{*: Statistically significant.}

$\mathrm{p}$ : $\mathrm{p}$ value for comparing between the studied periods

$\mathrm{p}_{1}: \mathrm{p}$ value for comparing between baseline and after one month

$\mathrm{p}_{2}: \mathrm{p}$ value for comparing between baseline and one month of treatment

$\mathrm{p}_{3}: \mathrm{p}$ value for comparing between after one month and one month of treatment

According to DLQI, there was no statistical significant difference between groups as regard baseline. There was statistical significant difference between groups as regard after one month and one month after end of Treatment.

In group A; as regard Dermatology Life Quality Index (DLQI), there was highly statistical significant difference between baseline and each of after one month and at one month after end of treatment. On the other hand, in group B; there was highly statistical significant difference between baseline and each of after one month and at one month after end of treatment (Table 3). 


\begin{tabular}{|c|c|c|c|c|c|}
\hline $\begin{array}{c}\text { Dermatology Life Quality } \\
\text { Index (DLQI) }\end{array}$ & Baseline & $\begin{array}{l}\text { After one month } \\
\text { of treatment }\end{array}$ & $\begin{array}{l}\text { One month after } \\
\text { end of treatment }\end{array}$ & $\mathbf{F}$ & $\mathbf{P}$ \\
\hline \multicolumn{6}{|l|}{ Study group A } \\
\hline Mean \pm SD & $21.73 \pm 3.01$ & $10.93 \pm 1.98$ & $10.13 \pm 2.53$ & \multirow[t]{2}{*}{233.597} & \multirow[t]{2}{*}{$<0.001^{*}$} \\
\hline Median (IQR) & $\begin{array}{c}22.0 \\
(21.0-23.50)\end{array}$ & $\begin{array}{c}11.0 \\
(10.0-12.0)\end{array}$ & $\begin{array}{c}10.0 \\
(8.0-11.50)\end{array}$ & & \\
\hline $\mathrm{P}$ between periods & \multicolumn{3}{|c|}{$\mathrm{p} 1<0.001^{*}, \mathrm{p} 2<0.001^{*}, \mathrm{p} 3=0.333$} & & \\
\hline Control group B & & & & & \\
\hline Mean \pm SD & $21.87 \pm 3.29$ & $13.93 \pm 3.10$ & $12.93 \pm 1.79$ & \multirow[t]{2}{*}{191.211} & \multirow[t]{2}{*}{$<0.001^{*}$} \\
\hline Median (IQR) & $\begin{array}{c}21.0 \\
(20.0-25.0)\end{array}$ & $\begin{array}{c}15.0 \\
(10.50-16.0)\end{array}$ & $\begin{array}{c}13.0 \\
(12.0-14.0)\end{array}$ & & \\
\hline
\end{tabular}

\section{*: Statistically significant}

$\mathrm{p}: \mathrm{p}$ value for comparing between the studied periods

$\mathrm{p}_{1}$ : $\mathrm{p}$ value for comparing between baseline and after one month

$\mathrm{p}_{2}: \mathrm{p}$ value for comparing between baseline and one month of treatment

$p_{3}: p$ value for comparing between after one month and one month of treatment

\section{DISCUSSION}

This study aimed to investigate the effect of transcutaneous electrical nerve stimulation on pruritus in lichen planus. Lichen planus (LP) is a persistent immune-mediated dermatosis with an unknown etiology. The condition can affect the skin, mucous membranes, nails, and/or hair follicles and has a wide range of clinical symptoms and subtypes. In cutaneous lichen planus the immune system attracts flexor surfaces of epithelial cells of the skin, which is indicated by a black area and rough scaly skin. There is also the development of lesions that are shinny and purple in appearance, with a flat topped papule covered by Wickham striae, a network of lines. In this stage of LP, 6" P's" can also be visible ${ }^{(12)}$.

With LP, long-term attacks can develop, lasting months to years and leading in a reduced quality of life (13). Itching is a common and distressing subjective symptom of LP. One of the main goals of LP management is to effectively address pruritus ${ }^{(7)}$. Various topical medications, including potent topical corticosteroids, have been investigated, but they are often useless, requiring the consideration of further therapeutic options ${ }^{(\mathbf{1 4})}$. TENS is a commonly nonpharmacologic and noninvasive pain treatment ${ }^{(15)}$.

TENS can cause neuromodulation through a variety of mechanisms, including presynaptic inhibition in the posterior horn of the spinal cord (gate control theory), and endogenous pain management by chemical release (e.g. endorphins, dynorphins and encephalins), and direct inhibition of excitation of abnormally firing nerves and restoration of afferent input ${ }^{(16)}$.

Our result shows that regarding visual analogue scale there was no statistical significant difference between groups as regard baseline. There was high statistical significant difference between groups as regard after one month and as regard one month after end of treatment according to visual analogue scale. There was also statistical significant difference between groups as regard after one month and one month after end of treatment according to DLQI.

The hypothesis of the current study was confirmed by the results, which revealed that TENS is beneficial and had a good effect on pruritus in lichen planus patients. This is in agreement with the findings of Waked et $\boldsymbol{a l} .{ }^{(9)}$ who showed a statistically significant $(\mathrm{P}<0.001)$ decline in mean VAS score at weeks 2 and 4 of therapy compared with baseline. Regarding DLQI measures, the results of the study showed that there was also a significant $(\mathrm{P}<0.001)$ improvement in DLQI scores at week 4 after treatment compared with baseline and $65 \%$ of patients had an improvement of $>50 \%$ in median DLQI. This improvement in Quality Of Life (QOL) measures may be attributed to the significant decline in itching intensity.

The results of the present study are consistent with those of Yuksek $\boldsymbol{e t} \boldsymbol{a l}{ }^{(\mathbf{8})}$ who demonstrated that TENS reduces the severity of itching and its impact on the patient's daily life. The results showes that TENS treatment has a positive impact on DLQI and VAS values in lichen simplex (LS) and macular amyloidosis (MA) induced pruritus. TENS is a successful therapy for LS and MA pruritus, according to patient-reported results, including treatment assessment score.

According Tinegate and McLelland ${ }^{(16)}$, TENS may provide relief from pruritus in patients who have failed to respond to conventional treatments, TENS can be combined with other pruritus relief methods.

The findings of this study agree with that of Abdelhalim (17), which confirms the efficacy of TENS in relieving pruritus in lichen simplex chronicus (LSC) patients and these findings may attribute to the mechanism of TENS.

The results of the present study are consistent with those Mohammad Ali et al. ${ }^{(18)}$ who demonstrated that TENS treatment is associated with a significant 
positive influence on VAS scores in atopic dermatitis (AD), LSC, and to a lesser extent in liver diseaseinduced pruritus, as well as a high level of safety. As a result of the significant reduction in pruritus, the inflammatory lesions of the skin improved, and the dermatologist-reported clinical efficacy outcomes also improved.

\section{CONCLUSION}

According to our results, TENS was beneficial and had a good effect on pruritus in lichen planus patients and provided significant improvement in its itching.

\section{FUTURE STUDIES AND RECOMMENDATIONS}

1- It was recommended to add TENS as an integral part of treatment for pruritus of lichen planus.

2- Further studies are needed to study the effects of transcutaneous electrical nerve stimulation on lichen planus patient.

\section{REFERENCES}

1. Mobini N, Toussaint S, Kamino H (2005): Noninfectious erythematous, papular, and squamous siseases. In: Lever's Histopathology of the Skin, $9^{\text {th }}$ edn (Elder DE, Elenitsas R, Johnson BL, Murphy GF, eds). Philadelphia: Lippincott Williams and Wilkins; Pp. 180-214.

2. Le Cleach L, Chosidow O (2014): Lichen planus. N Engl J., 366: 723-732.

3. Lewis M, Jordan R (2012): Oral medicine ( $\left.2^{\text {nd }} e d.\right)$. London: Manson Publishing. Pp. 66-72.

4. Weston G, Payette M (2015): Update on lichen planus and its clinical variants. Int J Womens Dermatol., 1(3):140-9

5. Welz-Kubiak K, Reich A (2013): Mediators of pruritus in lichen planus. Autoimmune Dis., 13: 941431.

6. Sun Y, Zhao Z, Meng X et al. (2009): Cellular basis of itch sensation Science, 325: 1531-534.

7. Waked I, Ibrahim Z, Elgohary H (2019): Does transcutaneous electrical nerve stimulation have an antipruritic effect in lichen planus? A randomized clinical trial. Clin Exp Dermatol., 44(3):252-256.
8. Yuksek J, Sezer E, Aksu M et al. (2011): Transcutaneous electrical nerve stimulation for reduction of pruritus in macular amyloidosis and lichen simplex .J Dermatol., 38: 546-52.

9. Tang W, Chan L, Lo K et al. (1999): Evaluation on the antipruritic role of transcutaneous electrical nerve stimulation in the treatment of pruritic dermatoses. Dermatology, 199: 237-241.

10. Langner M, Maibach $H$ (2009): Pruritus measurement and treatment. Clin Exp Dermatol., 34: 285-288.

11. Shikiar R, Harding G, Leahy $M$ et al. (2005): Minimal important difference (MID) of the Dermatology Life Quality Index (DLQI): results from patients with chronic idiopathic urticaria. Health Qual Life Outcomes, 20: 36-42.

12. Gorouhi F, Davari P, Fazel N (2014): Cutaneous and mucosal lichen planus: A comprehensive review of clinical subtypes, risk factors, diagnosis, and prognosis. The Scientific World Journal, 10: 742826.

13. Gorouhi F, Solhpour A, Beitollahi J et al. (2007): Randomized trial of pimecrolimus cream versus triamcinolone acetonide paste in the treatment of oral lichen planus. J Am Acad Derm., 57(5): 806-13.

14. Carbone M, Arduino P, Carrozzo M et al. (2009): Topical clobetasol in the treatment of atrophic-erosive oral lichen planus: a randomized controlled trial to compare two preparations with different concentrations. J Oral Pathol Med., 38(2):227-233.

15. Sluka K (2008): The Neurobiology of pain and foundations for electrical stimulation. In Clinical Electrophysiology. Edited by Robinson AJ, SnyderMackler L. Philadelphia: Lippincott Williams \& Wilkins, Pp. 107-149.

16. Tinegate $\mathbf{H}$, McLelland $\mathbf{J}$ (2002): Transcutaneous electrical nerve stimulation may improve pruritus associated with haematological disorders. Clin Lab Haematol., 24: 389-90.

17. Abdelhalim N (2014): Capsaicin phonophoresis versus transcutaneous electrical nerve stimulation in the treatment of pruritus in lichen simplex chronicus: A Prospective Randomized Controlled Study. Int J Health Sci Res., 4(11):140-149.

18. Mohammad Ali B, Hegab D, El Saadany H (2015): Use of transcutaneous electrical nerve stimulation for chronic pruritus. Dermatol., 28: 210-15. 